\title{
Theatre production: a positive metaphor for dementia care-giving
}

\author{
Christine Brown Wilson ${ }^{1 \star}$ (D), Jan Hinson ${ }^{2}$ (D), Jacinda L. Wilson ${ }^{3}$ (D), Stephanie Power ${ }^{3}$ (D), \\ Daniel Hinson ${ }^{2}$ and Andrea Petriwskyj ${ }^{3}$ \\ ${ }^{1}$ School of Nursing and Midwifery, Queens University, Belfast, UK, ${ }^{2}$ Social Work, School of Allied Health, \\ Australian Catholic University, Brisbane, Australia and ${ }^{3}$ School of Nursing, Midwifery and Social Work, \\ The University of Queensland, Brisbane, Australia \\ ${ }^{*}$ Corresponding author. Email: c.brownwilson@qub.ac.uk
}

(Accepted 4 March 2021; first published online 14 April 2021)

\begin{abstract}
Language can shape and reinforce attitudes and stereotypes about living with dementia. This can happen through use of metaphors. However, common metaphors may not capture the complexity of experience of dementia from the perspective of the individual person or a family carer. This paper presents an alternative metaphor - that of a theatre production - based on the strategies used by carers to support people with dementia to live well in the community. We conducted face-to-face semi-structured interviews with 12 family members caring for someone with dementia in the community in Queensland, Australia. Our aim was to explore the strategies these carers used to provide support. Interview recordings were fully transcribed and thematically analysed. We identified positive care-giving strategies that described multiple roles that carers fulfilled as they felt increasingly responsible for day-to-day decision making. Family carers explained how they supported the person with dementia to remain a central character in their life and continued to support the person to be themselves. To achieve this, family carers embodied roles that we identified as similar to roles in a theatre production: director, stage manager, supporting cast, scriptwriter, and costume designer and wardrobe manager. Our metaphor of a theatre production offers a fresh perspective to explore the experience of informal care-giving in the context of dementia.
\end{abstract}

Keywords: care-giver; dementia; metaphor; attitudes; language; stereotypes; qualitative research

\section{Introduction}

Dementia is a major public health issue with over 50 million people worldwide affected and 10 million new cases each year (World Health Organization, 2017). Dementia generally refers to a syndrome related to changes in cognitive brain function resulting in a loss of capacity in undertaking activities of everyday life (Burns and Iliffe, 2009).

(C) The Author(s), 2021. Published by Cambridge University Press. This is an Open Access article, distributed under the terms of the Creative Commons Attribution licence (http://creativecommons.org/licenses/by/4.0/), which permits unrestricted re-use, distribution, and reproduction in any medium, provided the original work is properly cited. 
Having dementia does not mean the person is unable to participate actively in community life. It also does not mean they cannot participate in making decisions about health and express their perspectives (Mariani et al., 2017). Indeed, many people living with dementia actively campaign for recognition of the person with dementia and for changes to the health and social care systems internationally (Swaffer, 2014).

Although it is recognised that people living with dementia and their carers should be empowered, the prevailing medical discourse surrounding dementia is one of decline and loss of capacity. This perpetuates ongoing negative attitudes influencing the dementia narrative (Zimmerman, 2017). For example, referring to people living with dementia as sufferers or victims reinforces the person as helpless and diminishes their dignity and self-esteem (Swaffer, 2014; Alzheimer's Society, 2018; Dementia Australia, 2018). People with dementia remain labelled with pejorative titles associated with behaviours such as 'wanderer, screamer or hitter', which can negatively impact the way others relate to them and result in them being seen as problems to be managed (Cunningham et al., 2019: 1110). This often creates tension for carers in delivering person-centred care as they seek to support autonomy, dignity, respect, empowerment and positive risk-taking in the person with dementia, while readjusting psycho-social approaches and navigating behaviour changes (Hobson, 2019).

Language is an important part of understanding about dementia because it influences how we think and behave. As one significant form of shared language, metaphors are used to describe experience and emotions particularly related to illness where no standard vocabulary exists. Over time, metaphors become standardised language and influence how we perceive the conditions to which they refer (George, 2010).

Metaphors are often used to describe the experience of having dementia, providing a sense of continuity for those experiencing illness in bridging the past and present or to explain the caring experience (Zimmerman, 2017). Golden et al. (2012: $148,149)$ studied transcripts of 19 support group meetings attended by spouses of people with dementia and identified a number of metaphorical constructions of the dementia experience: journey (e.g. 'drifting along'); machine or circuit (e.g. 'system is beginning to shut down'); orientation (e.g. people with dementia have their 'ups and downs'); harm or abuse (e.g. care-givers as 'falling apart'); game (e.g. 'Russian Roulette'). Military metaphors such as 'fighting', 'battle' and 'war on' are also sometimes used in medical literature about dementia (Lane et al., 2013). However, some metaphors, such as these military-related ones, may not be helpful and should be used with care because they have the power to influence negatively how dementia is perceived (Lane et al., 2013).

In addition, Zimmerman (2017) reviewed English, French and German texts and found metaphors used by people with dementia may not align with those of their carers. While people with dementia referred to a journey that supported them in gaining insights into their illness, carers tended to refer to the person with dementia as journeying away from them to a place they were not able to go. People with dementia also used life-affirming metaphors that spoke to their remaining abilities, whereas carers may see decline and use metaphors such as an 'empty shell' (Zimmerman, 2017: 81). This carer-held perception may make it more likely to 
see the person with dementia as lacking in ability because of their level of dependency. However, not all carers hold this perspective. In his commentary, George (2010: 587) drew on his own experience as a carer of someone with dementia in discussing the use of language: 'It is important to choose language that brings out the dynamism of the caregiver role rather than letting the burden clichés win out.'

We seek to move beyond the concept of burden and consider alternative ways of viewing the care provided by family carers in supporting the person with dementia to live well in the community. Our research explored the experiences of family carers of a person with dementia living in the community. We aimed to identify the positive strategies carers used to manage their day-to-day lives, which also) considered the activity family carers undertook to support the person with dementia to continue to live their lives. This led us to identify the metaphor of theatre production, which positively describes the many roles fulfilled by family carers and their supporting cast.

\section{Methodology}

This research was conducted in Queensland, Australia, in 2016 and 2017, using an interpretivist framework. The researchers explored how participants managed their daily life when caring for a person with dementia by eliciting participants' subjective experiences (Flynn and McDermott, 2016). Carers shared the daily issues they dealt with in caring for the person with dementia, providing insights into the ways they constructed the social fabric of their lives (Engel and Schutt, 2014). These insights were used to create meaningful representations of the carer's experiences (Vicars and McKenna, 2015).

Approval for the research was granted by The University of Queensland Human Research Ethics Committee. Participants gave written consent. All interviews were digitally recorded with permission and verbal consent was recorded at the time of the interview. Participants were reminded that they could stop the interview or withdraw from the study at any time, without penalty.

Service providers and consumer organisations advertised the project in newsletters, at conferences and at support group meetings. Carers who expressed interest in participating were sent an information pack containing a consent form and a demographic questionnaire. Inclusion criteria were being (a) a primary carer for an individual with dementia and (b) currently engaged in care-giving in the community.

Face-to-face semi-structured interviews were conducted with 12 people caring for a family member with dementia living in the community. All carers had responsibility for supporting the person living with dementia in personal hygiene, meals, medication management and social activities, as well as undertaking general household duties such as the cleaning, laundry and shopping (Table 1). Carer interviews lasted between 30 and 100 minutes (average of 90 minutes) and were conducted in a discursive style. Interviews were conducted at private residences or alternative locations in the community or in residential villages. The interviewer was an academic social worker $(\mathrm{JH})$ with many years' practice and management experience in the areas of health and trauma. 
Table 1. Characteristics of family care-givers

\begin{tabular}{|c|c|c|c|c|c|c|}
\hline $\begin{array}{l}\text { Age } \\
\text { group }\end{array}$ & Gender & $\begin{array}{l}\text { Relationship to } \\
\text { PWD }\end{array}$ & $\begin{array}{c}\text { Co-habiting with } \\
\text { PWD }\end{array}$ & $\begin{array}{l}\text { Hours spent caring for } \\
\text { PWD }\end{array}$ & In employment & $\begin{array}{l}\text { Caring for other } \\
\text { dependants }\end{array}$ \\
\hline $90+$ & Male & Spouse & Yes & 24 & No & No \\
\hline $80-89$ & Male & Spouse & No & 24 & No & No \\
\hline $80-89$ & Male & Spouse & No & 24 & No & No \\
\hline 70-79 & Female & Spouse & Yes & $\begin{array}{l}\text { Full-time when not in } \\
\text { respite }\end{array}$ & No & No \\
\hline 50-59 & Female & Spouse & Yes & 24 & No & Yes \\
\hline $60-69$ & Female & Daughter & Yes & 24 & No & No \\
\hline
\end{tabular}




\section{Data analysis}

Interviews were transcribed and analysed thematically in NVivo version 10 (QSR International, Melbourne). All data were anonymised, and pseudonyms were used to protect participant confidentiality. The data were independently analysed by two of the research team members (SP and JLW), using a 'bottom-up' approach that was flexible and open to what surfaced during analysis (Braun and Clarke, 2013). These team members independently read the data and undertook preliminary coding in NVivo that identified specific strategies undertaken by the family carer (Table 2). They then met to confer and review initial themes, as identified in Table 2. Through further discussion and co-analysis, they reconciled the findings, refined the themes and reached a consensus that was then reviewed by the wider research team.

\section{Findings}

Many of the strategies that carers focused on were enabling the person with dementia to be 'themselves': these strategies were identified as important to maintain the core of who they were. This analysis led us to identify a theatre production metaphor because the strategies went beyond individual discrete activities to form an overall production that enabled the carer and person with dementia to maintain their relationship and continue activities and roles that gave their lives meaning.

Care-giving strategies that supported the metaphor of theatre production included directing the person with dementia to undertake activities they enjoyed doing, providing them with a 'script' to follow and managing their wardrobe. Carers also managed the 'production' of daily life similar to a stage manager co-ordinating a theatre production and engaged a supporting cast. These roles positioned the person living with dementia as the central character and identified the range of strategies carers use to support the person living with dementia to remain themselves and maintain valued roles. Notably, as the direction increased from the carer, the individual with dementia remained centre stage.

\section{Director}

In the context of a theatre production, directors collaborate in many ways to ensure those involved in the theatre production feel a sense of ownership of the production (Knopf, 2017). For the carers in this study, the purpose of direction was to support the person with dementia to maintain and perform valued roles and relationships. Similar to the director of a theatre production, carers attempted to generate energy and goodwill to encourage the person with dementia to work towards shared goals. In our study, carers used direction to enable the person with dementia to play the fullest role possible.

Directors articulate their vision for a production and empower the cast members to be creative within their own spheres of influence (Knopf, 2017). For example, some carers sought to manage interactions with other actors to ensure the person with dementia could be involved in decision making for as long as possible: 
Table 2. Summary of thematic analysis: the roles embodied by carers and positive strategies to support people to live well with dementia through the metaphor of theatre production

\begin{tabular}{|c|c|c|}
\hline Theme - roles & $\begin{array}{c}\text { Sub-theme - general } \\
\text { strategy }\end{array}$ & Codes - specific strategies \\
\hline Director & Enables collaboration & $\begin{array}{l}\text { - Manage interactions with other actors } \\
\text { to enable the person with dementia to } \\
\text { be involved in decision making } \\
\text { - Take on everyday decision making as } \\
\text { required when the person with } \\
\text { dementia demonstrates they are } \\
\text { unable or unwilling } \\
\text { - Take on all decision making for } \\
\text { unplanned change when the person } \\
\text { with dementia is no longer able to } \\
\text { perform certain roles }\end{array}$ \\
\hline Stage manager & $\begin{array}{l}\text { Provides practical } \\
\text { support }\end{array}$ & $\begin{array}{l}\text { - Identify appropriate times to manage } \\
\text { and provide practical support to } \\
\text { enable the person with dementia to } \\
\text { continue to play their role } \\
\text { - Procure props or aides used for } \\
\text { everyday life 'production' and assist } \\
\text { the person with dementia to maintain } \\
\text { some independence } \\
\text { - Organise and manage external services } \\
\text { that are involved as part of the } \\
\text { supporting cast } \\
\text { - Withstand pressures to provide and } \\
\text { maintain levels of practical support } \\
\text { every day and throughout each day }\end{array}$ \\
\hline Support cast & $\begin{array}{l}\text { Provides practical and } \\
\text { emotional support }\end{array}$ & $\begin{array}{l}\text { - Continue to provide direction and } \\
\text { management of care-giving } \\
\text { - Initiate and direct wider circle of } \\
\text { support, e.g. extended family, support } \\
\text { groups or external services } \\
\text { - Support groups provide connection for } \\
\text { carers and others in similar roles } \\
\text { - Formal services provide practical } \\
\text { support to carer }\end{array}$ \\
\hline Scriptwriter & $\begin{array}{l}\text { Provides dialogue and } \\
\text { direction }\end{array}$ & $\begin{array}{l}\text { - Give implicit direction through subtle } \\
\text { risk management cues and strategies } \\
\text { - Give implicit direction through careful } \\
\text { wording (scripts) } \\
\text { - Give explicit direction through written } \\
\text { or verbal reminders and instructions }\end{array}$ \\
\hline $\begin{array}{l}\text { Costume designer } \\
\text { and wardrobe } \\
\text { manager }\end{array}$ & $\begin{array}{l}\text { Ensures maintenance } \\
\text { of identity }\end{array}$ & $\begin{array}{l}\text { - Provide practical support through } \\
\text { everyday task of getting dressed: } \\
\text { - Explicit guidance } \\
\text { - Implicit guidance } \\
\text { - Balance practical support with } \\
\text { respecting and assisting the person } \\
\text { with dementia to maintain their } \\
\text { self-identity }\end{array}$ \\
\hline
\end{tabular}


My wife had two uncles that ... nominated [her] as executor ... And I thought 'well, we'll leave it as it is, but I'll have to guide her hand and tell her how to sign everything'. So that was working reasonably well, but then the solicitors wanted to talk to her specifically, and they'd ring her up, and say 'well do you agree with this...' ... And she'd say yes to everything and didn't understand a thing. If I asked her what they said, she couldn't remember a thing either. So that was quite a difficult phase, I had to say, 'you talk to me in future'. (Tom, caring for wife)

When the maintenance of certain decision-making roles was no longer possible, or the person with dementia demonstrated they were unable or unwilling to maintain them, carers attempted to generate a level of ownership by the person with dementia in everyday decision making. However, as the dementia progressed, there appeared less collaboration:

He's got to have direction all the time ... Sometimes he doesn't like direction. He hates it when I say 'you haven't had your tablets, and you need to have your tablets'. You just have to persist because you know there's things that have to be done ... and you've sort of got to be on the ball all the time. (Mary, caring for husband)

But I'm noticing, I have to take on more responsibility. Like he used to manage all the money and all that sort of thing, but I do that now. He's lost the ability to do that acute problem solving. (Annette, caring for husband)

Although the role of director is to empower cast members within their sphere of influence, the person with dementia's sphere of influence changed as the dementia progressed and, as such, the production had to be adapted:

But you've got to make these hard decisions, so I ended up recruiting another [support worker] for the job. And then well I realised ... he's not making any decisions since the accident. He never made another decision again. (Annabelle, caring for husband)

...it's very hard to know when you step in, and the role changes, you have to sort of take over and say, 'okay this is what you're doing Mum'. But I can't go [out of the house] for long, because I've taken this role on, I don't feel that I can hand it over to anyone else. (Renee, caring for mother)

The carers in our study described direction along a continuum. This began with collaborative approaches to engage the person with dementia to support the continuation of valued roles, moving towards more overt direction as these roles became increasingly difficult to maintain. This suggests an ongoing tension for the carer as they attempt to involve the person with dementia in everyday decision making with the realisation that they are not always able to engage in decisionmaking roles. The carer, as director, needed to recognise the inherent change in dynamics as roles were adapted or changed in the production. 


\section{Stage manager}

Although directors are responsible for the integration of the performance within theatre productions, stage managers provide practical support and organisation to the director, actors and others involved in the production process (Apperson et al., 1998). Some carers saw their role as a management process, which often meant managing behind the scenes through verbal prompts, thus providing background rather than overt support for the person with dementia to enable them to continue to play their part:

I walked with him to the Men's Shed and I walked home, and I said 'now you take me to the Men's Shed'. So, he took me to the Men's Shed and I had to then point things out on the way like landmarks that he would recognise so that he knew that he was going the right way. (Annette, caring for husband)

...she picks up the leaves in the garden, and I say 'well, just pick the weeds out, not the leaves'. (Tom, caring for wife)

Stage managers are also responsible for procuring props or aids for the production. Some carers described how they procured aids to assist the person with dementia to maintain some independence:

I bought a digital watch so he can read the time. He lost the house keys three times so I now have the keys on a lanyard ... with it around his neck ... he'd pull his hanky out of his pockets and the keys would come as well. (Annette, caring for husband)

These aids served both as practical supports and as props to support the stage management process, enabling the person with dementia to remain independent as above, or to remain living with the carer as below:

She's settled now, but when she first came [to daughter's home], she was getting up in the night and falling over. So, you know, little by little ... I put a bar across one side of the bed, and I've moved her bed so she can't fall out. I've got non-slip stuff on the floor now, so she won't fall over. (Renee, caring for mother)

Where community or paid services were part of the supporting cast, the carer as stage manager was involved in organising and managing these services, which was a time-consuming, constant and tiring task:

...I was working full-time co-ordinating all of mum's stuff ... I've worked pretty hard to co-ordinate a schedule for her so that she's got at least some point of contact every day. But the thing with Alzheimer's, is it changes constantly ... So, then you get all these things in place, but then the condition changes, so you need to adjust. So that's exhausting as well, because you'll just get something working and then, you know that you're going to need more services. We're coming up to a period now where we'll need to review it again. (Carrie, caring for mother) 
Participants also spoke of different pressures they experienced as they were required to provide constant levels of practical support in this role of stage management across the day:

Anything that he wants to do, I actually have to be doing alongside him. And that's emotionally wearing ... At the weekend, it's quite a nightmare. He'll talk at me all the time, asking me the same thing. (Jen, caring for her husband)

Sometimes I would love someone to come and shower him, but ... last year ... someone would come ... to shower him. But because of his incontinence I didn't want him waiting and sometimes they didn't get here until 10 o'clock so I would have him showered and dressed and everything by then. (Ruby, caring for her husband)

As stage manager, the carer organised and managed care with a focus on maintaining valued relationships and roles of the person with dementia. However, this management sometimes generated physical, emotional and psychological pressures for the carers that placed a strain on the relational dynamics between carer and the person with dementia.

\section{Supporting cast}

Within the overall direction and management of the day-to-day care-giving, a supporting cast was required to provide practical and emotional support. Supporting casts can include support groups, formal services and family members. For some carers, the supporting cast included members of a support group, which provided them connection with others in similar roles:

I do go to some of the ... they're called carers meetings. Well, to me the most important thing apart from [community agency] has been meeting other people with whom I can relate. (Jen, caring for husband)

Carers also spoke about support from formal services that enabled them to do things where it was not always possible to involve the person with dementia. In this way, the supporting cast performed practical roles that stepped into care-giving:

And just occasionally, if I needed to go anywhere, someone would come from [support organisation] and would take him for the day. Well, that was fine, he was quite happy to do that. (Polly, caring for husband)

I don't think that's entirely uncommon in care-giving situations, that one person ends up ... in the family, even if you've got a big family, one person ends up doing most of the work. The challenges are really more to do with the rest of the family. Like you know, getting the support that you need from them ... And eventually I got the older sister to talk to the younger sister to get her to do two nights as well. (Carrie, caring for mother)

It often fell to the carer to initiate and direct support from the wider family, support groups or formal services. In this scenario, the carer role was one of stage 
management to ensure the supporting cast were in the right place at the right time to enable the person with dementia to continue playing their role:

I had to find other things for him to do and ask him what he would want to do ... I was still at the stage of trying to keep things normal ... so that's why I've, the walking and stuff. So he's, he has conversations with, you know, the different people from the Heart Foundation that he walks with ... and I'm sure they all know that he's got dementia ... but they still walk with him. (Annette, caring for husband)

Some carers also described a reduction in their supporting cast:

The other thing I'm finding too, is that if I mention to people that she's got a mental problem, then what normally happens is they don't want to know us, so ... So, we're losing a lot of contacts that way, we're losing a lot of friendships that way. (Tom, caring for wife)

This loss of supporting cast meant that previous roles and relationships began to diminish. This lack of a supporting cast made it more difficult for the carer to maintain the valued roles and relationships of the person with dementia.

\section{Scriptwriter}

The role of a scriptwriter is to provide dialogue for the theatre production and to write directions for the actors (Smiley and Bert, 2005). The carers in this study spoke about the need to provide a script to enable the person with dementia to continue valued roles. Carers spoke of giving directions, which included implicit and explicit direction in the dialogue of their instructions.

\section{Explicit direction}

Sometimes explicit direction was required to support and guide the person with dementia, often through written or verbal reminders and instructions:

I write him out a shopping list and he goes and does the shopping. (Annette, caring for husband)

And if she asks you something I'll say 'it's all written down, it's up on the noticeboard ... I've written everything out for you' and if she asks me the question five times I give her the answer five times. (Warren, caring for mother)

\section{Implicit direction}

A scriptwriter must be able to empathise with the emotional state of the audience and the actors (Smiley and Bert, 2005). Carers demonstrated this in their directions through use of language and behaviour that was sensitive to the emotional state and emotional needs of the person with dementia. For example, sometimes carers gently directed actions in subtle ways:

At night-time, he would just want to get out of bed and go out. I had to gently dissuade him from that. And I think that's quite a common phenomenon isn't 
it? I made sure the doors were locked, and I kept the keys well out of reach. If he would want to start wandering, I'd just take him back to bed. Say 'it's time to sleep now'. (Polly, caring for husband)

To minimise the stigma often associated with dementia, some words were deliberately not included in scripts used by family or carers:

Because he doesn't think there is anything wrong with him. I mean I very rarely mention the word Alzheimer's. I usually say 'your memory is not so hot. And your sense of direction too is terrible'. (Pat, caring for husband)

These written and verbal instructions became scripts that were provided to the person living with dementia to support their involvement in ongoing valued roles or to support autonomy in maintaining their sense of control over their role.

\section{Costume designer and wardrobe manager}

Concerns about clothing choice and dressing were mentioned by many carers because dementia disrupts the ability of the person to dress themselves. However, clothing remains significant for maintaining the identities of people living with dementia (Twigg and Buse, 2013). In a theatre production, costumes 'stem from both the way a character is played and, in turn, influence the way a character is played' (Reid, 2000: 2). The wardrobe manager ensures the right clothing is available for the right part and decides which costumes and accessories are relevant to the part being played. In the same way, these carers described how they take responsibility for ensuring the person with dementia could maintain their sense of identity:

If I want him to look nice when I go out, I have to get his clothes out ... lay his clothes out ... otherwise he won't put something on that I think is suitable. If I don't want him to look special, I just let him go. He just gets dressed in whatever. (Annette, caring for husband)

I could usually put the clothes out and he can get dressed. I put them out every day. I turn the bed down at night. Put the pyjamas on the bed. Because otherwise he'll just go to bed in his clothes. Or he'll just lie on top of the bed. If I don't check he'll just go to bed in his underpants and not get into his pyjamas. (Mary, caring for her husband)

Being able to dress oneself remains important for people living with dementia with the loss of competence potentially threatening that person's continuity of self (Buse and Twigg, 2015). However, this was balanced with how the person was seen by others:

Sometimes he'll dress himself. Mostly if he does, he's got everything on back to front, and/or inside out. Which if we're around the house doesn't matter a lot, but if he's going to [support agency], I feel it's better if he doesn't have a polo on back to front. And, of course, it's so uncomfortable, he has shoes on the wrong feet, and he seems to do a fair bit of undressing and dressing again. And I have to be vigilant. (Jen, caring for her husband) 
As carers assumed the role of costume designer or wardrobe manager, they were able to ensure the person with dementia maintained their identity through dress. This helped them to support the person they were caring for to maintain the appearance of their role and of being themselves.

\section{Discussion}

This paper uses the metaphor of theatre production to elucidate family carer roles that may not be fully understood by formal services. People rely on metaphor as a cognitive means for understanding complex experiences and sharing them with others, providing 'a window into the way individuals experience and understand the world, including highly sensitive experiences such as illness and health' (Castano, 2020: 116). The theatre production metaphor provides a positive framework through which to understand changing roles, tensions, shifting responsibilities and strategies used to support the person with dementia in living their lives.

Family carers often experience a tension between honouring the person and making decisions for them. This study has recognised the inherent tensions for carers negotiated through their roles as director, stage manager, scriptwriter, and costume designer and wardrobe manager. These roles were adopted or evolved as the needs of the person with dementia changed, thereby impacting the dynamics of the relationship.

The human experience is inherently connected to agency, identity and expression, which can be conveyed and understood through language and performance (Bakhshi et al., 2008). A theatre production metaphor presents the strategies of carers as a way of supporting continuation of valued roles and activities in the ongoing story of the individual. Theatrical performances themselves may be seen as ongoing metaphors for life, representing worlds beyond the life that the person watching the theatre production experiences (Leach, 2013). The metaphor of theatrical performance in this study is significant because 'as performance images the world' (Leach 2013: 18), it illuminates the alternative and often misunderstood realities of the carers and people with dementia.

Carers in this study assumed a director role to support daily activities, maintaining previous interests or ensuring the person with dementia was able to contribute to activities important to the relationship. This direction enabled the person with dementia to remain themselves and maintain roles they valued. Carers also adopted the role of stage manager as they provided organisation, props and aids, and co-ordinated the supporting cast to help maintain independence and autonomy. Lee et al. (2016) highlight that part of an organised and safe space is having physical aids and equipment nearby. Our study suggests that having an organised space was important not only for risk management but also to maintain independence. A planned yet personalised environment can enable safer and higher-quality care, and contribute to positive care-giving interactions and quality of life (Lee et al., 2016). An important aspect in maintaining this production was supporting the person with dressing as the outward continuation of their performance. Many carers managed this situation by creating order for the person to retain their ability to remain involved in the process, thus preventing the person with dementia being seen as less competent by not dressing appropriately (Buse and Twigg, 2015). Then, as the dementia progressed, the person living with dementia found it 
more difficult to remember or perform their 'part'; at this point the carer became a scriptwriter to support them to remember what to say or do.

Within each role, the carer organised and managed care with a focus on maintaining valued relationships and roles of the person with dementia. This is a key tenet of person-centred care (Brooker and Latham, 2016) that may be overlooked by services. In our study, the carer's role as stage manager was similar to that described as personcentred leadership (McCormack et al., 2017). As the dementia developed, the ability to maintain the roles of carer as manager and director and individual protagonist became difficult as the care needs, and thus the relationship, changed.

The general discourse in dementia is one where the person with dementia is 'experiencing a steady erosion of selfhood where nothing of the person remains' (Kontos and Naglie, 2007: 800). The approach described by carers in this paper suggests that carers may resist this discourse by directing and managing the performance where the person with dementia continues to play themselves even when they cannot always recall the details required to do so. This situation was depicted in The Iron Lady, the biographical drama film about Margaret Thatcher, where the carer continued to provide direction, script writing and wardrobe management to support her mother to maintain her role as a retired stateswoman. This suggests that carers are maintaining the embodied personhood, demonstrating the value of biography in the person with dementia's everyday life (Brooker and Latham, 2016).

However, this approach is not without its challenges, as demonstrated by these films produced in the early 2000s: Iris, Away From Her and The Iron Lady (Orr and Teo, 2015; Schweda, 2019). If we start from the assumption that every script is open to interpretation, the director's primary responsibility could be defined as articulating a vision for - and with - the person with dementia and any supporting cast. If carers are unable to accommodate the subjectivity of the family member with dementia, a loss of self may result where the person with dementia follows a path into forgetfulness (Kontos and Naglie, 2007; Schweda, 2019). The data presented in this paper demonstrate how carers adopt many roles to support the personhood of the person with dementia alongside the challenges they face as they constantly renegotiate these roles.

A key challenge for the carers in this study was engaging a supporting cast of services, networks and families that enabled the person with dementia to play the central role of themselves. Carers reported being uncertain about when service providers would arrive at their house, e.g. to provide personal care to the person with dementia. This situation can lead to the carer not being able to relinquish some roles in the theatre production because the formal carers have 'missed their stage cue'. The metaphor of a theatre production may enable services to more effectively play the role of the supporting cast while also undertaking some of the additional roles undertaken by the family carer. For example, formal services may act as stage managers if they place a greater focus on the lifestyle of the person with dementia and promote opportunities that maintain valued roles and activities of the person with dementia when designing and delivering formal care. Because people with dementia have difficulties in expressing themselves, the metaphor of theatre production may cultivate an understanding (and adaptation) of a fluid, evolving and flexible approach to person-centred care by community-based services. 
The metaphor of theatre production embraces the reality of caring for someone with dementia while acknowledging positive aspects of the experience. In his commentary, George was encouraged to see some shift in metaphors used for dementia:

Finally, a shift away from the metaphors that portray caregiving as a state of constant bereavement may emancipate the full spectrum of emotions felt by caregivers: not just the deep sadness and distress that are intrinsic to the experience, but also the humour, love, compassion, forgiveness, reconciliation, and other sentiments involved in caring for a loved one with dementia. (George, 2010: 587)

We present our metaphor of a theatre production as one that allows us to understand some of the complexity and nuance within the reality of carers' roles and experiences.

\section{Limitations}

Our study did not include the views of people with dementia because we wanted to understand the experience and perspective of family carers in how they enact and describe their specific roles. This is not intended in any way to diminish the agency of people living with dementia in actively continuing their valued roles, including decision making and managing care, or their own perspectives on these roles.

There is a likely self-selection bias in our study because many participants are active in dementia advocacy, so may be more motivated and able to express their views and relate their experiences than carers who do not belong to such advocacy groups. A further limitation is that our study did not include the perspective of a son caring for a father with dementia or of a parent caring for a child with dementia. Additionally, no individuals who identified as Aboriginal or Torres Strait Islander volunteered for the study, which means their voices are not represented here.

We did not have the opportunity to return to carers to ask them if the metaphor of theatre production resonated with their lived experience. However, metaphor supports people to understand the lived experience of those experiencing and caring for a person with dementia (Zimmerman, 2017; Castano, 2020). Future work should explore how this metaphor resonates with carers of people living with dementia and how it may be useful to reframe their experience for others.

There is also the potential to explore the roles of others using the theatre metaphor. Our study explores carers' perspectives on the ways they work to support and promote that agency and personhood, and the challenges and tensions they encounter. In the context of this study, stage direction was often an adaptation to the person with dementia not being able to maintain their valued roles independently. Future research using this metaphor should explore in more depth the roles of the person living with dementia in this dynamic production. Carers also tended to take on or not relinquish roles because services were not providing support at key times (when it is most needed) or did not provide the service required. Although our study produced limited data about how formal services might take on some of these roles, we are keen to use the theatre metaphor in future studies to investigate how interactions between carers and formal service providers can and do support the person with dementia to be themselves. 


\section{Conclusions}

The study reported here demonstrates how carers take an active role in the direction and management of the care of the person with dementia to support the person to continue valued roles and remain themselves. The terms 'direction' and 'management' could imply the potential disempowerment of people living with dementia; indeed, the data demonstrate the fine line carers negotiate between supporting the individual's autonomy while ensuring life is managed effectively. Viewing these roles through the metaphor of a theatre production provides a heuristic device to understand the changing pressures family carers are under when supporting the person with dementia to live their lives. As directors and stage managers, carers are responsible for the decisions required to maintain their lives while managing a supporting cast and props to support the maintenance and performance of valued roles for the person with dementia. We intend to conduct further research to explore how formal services could support carers as they undertake some of these roles to ensure the person with dementia can 'play themselves'. A theatre production metaphor offers a fresh perspective to explore the experience of care-giving in the context of dementia.

Acknowledgements. We thank the carers who participated in this study for sharing their insights and time. Our thanks also go to Grace Garnier (social work student, Australian Catholic University) for her library assistance. We also wish to acknowledge the role of Professor Jill Wilson and Associate Professor Cheryl Tilse (The University of Queensland) in the conception and implementation of this study and thank them for their support.

Author contributions. CBW and AP were involved in the conception of the study, JH was responsible for data collection, SP and JLW were responsible for data analysis, and all authors were involved in the writing of the manuscript and approved the final version.

Financial support. This work was supported by the School of Nursing, Midwifery and Social Work, The University of Queensland (internal grant).

Conflict of interest. The authors declare no conflicts of interest.

Ethical standards. Approval for the research was granted by The University of Queensland Human Research Ethics Committee (approval number 2015001727).

\section{References}

Alzheimer's Society (2018) Positive Language: An Alzheimer's Society Guide to Talking About Dementia. Available at https://www.alzheimers.org.uk/sites/default/files/2018-09/Positive\%20language\%20guide_0. pdf.

Apperson L, Kelly T and Aberger T (1998) Stage Managing and Theatre Etiquette: A Basic Guide. Chicago, IL: Ivan R. Dee.

Bakhshi H, Schneider P and Walker C (2008) Arts and Humanities Research and Innovation. Bristol, UK: Arts and Humanities Research Council (AHRC) and National Endowment for Science, Technology and the Arts (NESTA).

Braun V and Clarke V (2013) Successful Qualitative Research: A Practical Guide for Beginners. London: Sage.

Brooker D and Latham I (2016) Person-centred Dementia Care: Making Services Better with the VIPS Framework. London: Jessica Kingsley Publishing.

Burns A and Iliffe S (2009) Alzheimer's disease. BMJ 338, b158. 
Buse CE and Twigg J (2015) Clothing, embodied identity and dementia: maintaining the self through dress. Age, Culture, Humanities 2, 71-96.

Castano E (2020) Discourse analysis as a tool for uncovering the lived experience of dementia: metaphor framing and well-being in early onset dementia narratives. Discourse and Communication 14, 115-132.

Cunningham C, Macfarlane S and Brodaty H (2019) Language paradigms when behaviour changes with dementia: \#BanBPSD. International Journal of Geriatric Psychiatry 34, 1109-1113.

Dementia Australia (2018) Dementia Language Guidelines. Available at https://www.dementia.org.au/files/ resources/dementia-language-guidelines.pdf.

Engel RJ and Schutt RK (2014) Fundamentals of Social Work Research. Thousand Oaks, CA: Sage.

Flynn C and McDermott F (2016) Doing Research in Social Work and Social Care: The Journey from Student to Practitioner Researcher. London: Sage.

George DR (2010) Overcoming the social death of dementia through language. Lancet 376, 586-587.

Golden MA, Whaley BB and Stone AM (2012) 'The system is beginning to shut down': utilizing caregivers' metaphors for dementia, persons with dementia, and caregiving. Applied Nursing Research 25, $146-151$.

Hobson P (2019) Enabling People with Dementia: Understanding and Implementing Person-centred Care. Cham, Switzerland: Springer Nature.

Knopf R (2017) The Director as Collaborator. Abingdon, UK: Routledge.

Kontos PC and Naglie G (2007) Expressions of personhood in Alzheimer's disease: an evaluation of research-based theatre as a pedagogical tool. Qualitative Health Research 17, 799-811.

Lane HP, McLachlan S and Philip J (2013) The war against dementia: are we battle weary yet? Age and Ageing 42, 281-283.

Leach R (2013) Theatre Studies: The Basics. Abingdon, UK: Routledge.

Lee SY, Chaudhury H and Hung L (2016) Exploring staff perceptions on the role of physical environment in dementia care setting. Dementia 15, 743-755.

Mariani E, Vernooij-Dassen M, Koopmans R, Engels Y and Chattat R (2017) Shared decision-making in dementia care planning: barriers and facilitators in two European countries. Aging \& Mental Health 21, 31-39.

McCormack B, van Dulmen S, Eide H, Skovdahl K and Eide T (2017) Person-centred Healthcare Research. Hoboken, NJ: John Wiley Blackwell.

Orr DM and Teo Y (2015) Carers' responses to shifting identity in dementia in Iris and Away From Her: cultivating stability or embracing change? Medical Humanities 41, 81-85.

Reid F (2000) Designing for the Theatre. New York, NY: Routledge.

Schweda M (2019) Medical gazes and meteorological metaphors: representations of dementia in contemporary motion pictures. Israel Journal of Health Policy Research 8, 18.

Smiley S and Bert NA (2005) Playwriting: The Structure of Action, Revised Edn. New Haven, CT: Yale University Press.

Swaffer K (2014) Dementia: stigma, language, and dementia-friendly. Dementia 13, 709-716.

Twigg J and Buse CE (2013) Dress, dementia and the embodiment of identity. Dementia 12, 326-336.

Vicars M and McKenna T (2015) In the thick of things: drama as a qualitative methodology. Qualitative Research Journal 15, 416-429.

World Health Organization (2017) Global Action Plan on the Public Health Response to Dementia 20172025. Available at https://www.who.int/news-room/fact-sheets/detail/dementia.

Zimmerman M (2017) Alzheimer's disease metaphors as mirror and lens to the stigma of dementia. Literature and Medicine 35, 71-97.

Cite this article: Brown Wilson C, Hinson J, Wilson JL, Power S, Hinson D, Petriwskyj A (2023). Theatre production: a positive metaphor for dementia care-giving. Ageing \& Society 43, 89-104. https://doi.org/ $10.1017 /$ S0144686X21000428 